\title{
Prevalence of Helicobacter pylori Infection in Patients with Chronic Kidney Disease
}

\author{
Ji Yong Ahn \\ Department of Gastroenterology, Asan Medical Center, University of Ulsan College of Medicine, Seoul, Korea
}

See "Helicobacter pylori Infection in Patients with Chronic Kidney Disease: A Systematic Review and Meta-Analysis" by Suk Pyo Shin, et al. on page 628, Vol. 13. No. 6, 2019

There have been some debates about the association of $\mathrm{He}$ licobacter pylori infection and chronic kidney disease (CKD). Pathogenesis of $H$. pylori infection in patients with CKD is not clearly revealed and there are not enough studies about these two factors. There are several hypothesis which support that kidney disease may reduce $H$. pylori infection. High level of serum urea nitrogen can contribute to a decreased gastric acid secretion and higher gastric $\mathrm{pH}$ which could be the cause of lower prevalence of $H$. pylori among CKD. ${ }^{1}$ Inflammatory cytokines are also increased in CKD patients and it can cause gastric mucosal damage, chronic gastritis, and spontaneously eradicate H. pylori. ${ }^{2}$ In addition, antibiotics, proton pump inhibitors, or $\mathrm{H}_{2}$ receptor antagonists which are used in patients with CKD for long time might be associated with decreased $H$. pylori infection. $^{3}$

There are other hypothesis that are contrary to above theories. Some studies showed that high urea concentration makes the gastric mucosa more susceptible to $H$. pylori and infection rate is higher in uremic patients. ${ }^{4,5}$ And, in some articles which have studied about peptic ulcer in CKD, the prevalence of $H$. pylori infection looked lower compare to ulcer in non-CKD patients but real incidence may not be lower. ${ }^{6}$ Because the incidence of peptic ulcer is higher in CKD patients with various causes except H. pylori infection. ${ }^{7}$

In nationwide study of Taiwan, $H$. pylori infection rate is lower in peptic ulcer disease patients with CKD and end-stage renal disease (ESRD) than in those without CKD. ${ }^{6}$ On the contrary, recent meta-analysis studies showed no relation between $H$. pylori infection and CKD nor ESRD. ${ }^{8,9}$ However, those previous metaanalysis about the association between $H$. pylori infection and kidney disease have some selection biases. In this research, ${ }^{10}$ authors tried to minimize bias of previous meta-analyses and showed the results about the prevalence of $H$. pylori infection in patients with $\mathrm{CKD}$.

In this issue of Gut and Liver, Shin et al. ${ }^{10}$ included many articles compared to previous studies using systematic reviews and narrowed inclusion criteria to increase the accuracy of the results. Studies with only CKD patients were enrolled and other studies which have vague inclusion criteria including renal transplant recipients, diabetic nephropathy, or pediatric population were excluded. Authors compared the prevalence of $H$. pylori infection between CKD patients and control first, then showed subgroup analyses according to the modifiers.

In the 47 case-control or cross-sectional studies, CKD patients were 4,084 and controls without CKD were 6,908, and total prevalence of $H$. pylori infection in CKD patients was $48.2 \%$ and in controls was 59.3\%. Pooled analysis using 34 studies with same study design and statistical models supported significantly lower rate of $H$. pylori infection in CKD patients (odd ratio, 0.64; 95\% confidential interval, 0.52 to 0.79 ).

This meta-analysis ${ }^{10}$ showed lower infection rate of $H$. pylori in CKD patient with or without dialysis compare to nonCKD patients. Based on this research, there are some interesting points and further considerations. In this study, subgroup analysis showed the different results according to the methodological quality of included studies and significantly lower prevalence rate of $H$. pylori infection in CKD patients compare to controls was revealed in high qualified studies. In previous study which reported negative association of $H$. pylori with $\mathrm{CKD},{ }^{8}$ author showed trend of decreased risk of $H$. pylori infection in patients

\footnotetext{
Correspondence to: Ji Yong Ahn

Department of Gastroenterology, Asan Digestive Disease Research Institute, Asan Medical Center, University of Ulsan College of Medicine, 88 Olympic-ro 43-gil, Songpa-gu, Seoul 05505, Korea

Tel: +82-2-3010-5667, Fax: +82-2-476-0824, E-mail: ji110@hanmail.net pISSN 1976-2283 eISSN 2005-1212 https://doi.org/10.5009/gnl19310

(a) This is an Open Access article distributed under the terms of the Creative Commons Attribution Non-Commercial License (http://creativecommons.org/licenses/by-nc/4.0) which permits unrestricted non-commercial use, distribution, and reproduction in any medium, provided the original work is properly cited.
} 
with CKD in subgroup which had lower heterogeneity. These factors can be thought that, if studies can be focused to the adult CKD patients without renal transplant recipient or diabetes mellitus nephropathy, the prevalence of $H$. pylori infection may be clearly lower in CKD patients. This kind of clear result could pave the way for researchers to focus on the next step such as to clarify the reason of decreasing $H$. pylori infection in CKD patients.

This study, which was performed using statistical techniques of great effort, has important clinical meaning because authors found that $H$. pylori infection rate is lower in CKD patients compare to non-CKD patients. And they gave a message of importance about the well-designed study. Based on these results, further studies are expected to clearly the association between $H$. pylori and renal function and finally to contribute reducing the H. pylori infection.

\section{CONFLICTS OF INTEREST}

No potential conflict of interest relevant to this article was reported.

\section{ORCID}

Ji Yong Ahn

https://orcid.org/0000-0002-0030-3744

\section{REFERENCES}

1. Jaspersen D, Fassbinder W, Heinkele P, et al. Significantly lower prevalence of Helicobacter pylori in uremic patients than in pa- tients with normal renal function. J Gastroenterol 1995;30:585588.

2. Wesdorp RI, Falcao HA, Banks PB, Martino J, Fischer JE. Gastrin and gastric acid secretion in renal failure. Am J Surg 1981;141:334-338.

3. Gu M, Xiao S, Pan X, Zhang G. Helicobacter pylori infection in dialysis patients: a meta-analysis. Gastroenterol Res Pract 2013;2013:785892.

4. Hazell SL, Lee A. Campylobacter pyloridis, urease, hydrogen ion back diffusion, and gastric ulcers. Lancet 1986;2:15-17.

5. Luzza F, Imeneo M, Maletta M, et al. Helicobacter pylori-specific IgG in chronic haemodialysis patients: relationship of hypergastrinaemia to positive serology. Nephrol Dial Transplant 1996;11:120124.

6. Chang SS, Hu HY. Lower Helicobacter pylori infection rate in chronic kidney disease and end-stage renal disease patients with peptic ulcer disease. J Chin Med Assoc 2014;77:354-359.

7. Tseng GY, Lin HJ, Fang CT, et al. Recurrence of peptic ulcer in uraemic and non-uraemic patients after Helicobacter pylori eradication: a 2-year study. Aliment Pharmacol Ther 2007;26:925-933.

8. Wijarnpreecha K, Thongprayoon C, Nissaisorakarn P, et al. Association of Helicobacter pylori with chronic kidney diseases: a meta-analysis. Dig Dis Sci 2017;62:2045-2052.

9. Wijarnpreecha K, Thongprayoon C, Nissaisorakarn P, et al. Association between Helicobacter pylori and end-stage renal disease: a meta-analysis. World J Gastroenterol 2017;23:1497-1506.

10. Shin SP, Bang CS, Lee JJ, Baik GH. Helicobacter pylori infection in patients with chronic kidney disease: a systematic review and meta-analysis. Gut Liver 2019;13:628-641. 